\title{
Applying conditional process modelling to investigate factors influencing the adoption of water pollution mitigation behaviours
}

\author{
Murat Okumah $^{1}$ D . Priscilla Ankomah-Hackman ${ }^{2}$
}

Received: 12 May 2019 / Accepted: 24 January 2020 / Published online: 11 February 2020

(c) The Author(s) 2020

\begin{abstract}
Given that much of water resource pollution is behavioural in nature, understanding pro-environmental behaviour as well as the complex determinants of such behaviours is key to designing effective policies aimed at addressing the problem. The limited studies that attempt to explore the topic rely typically on first-generation statistical procedures, often failing to address the complexities of pro-environmental behaviour. We apply conditional process modelling to investigate potential determinants of behaviours aimed at mitigating water pollution-using an extended attitude-behaviour-context model. Results show that knowledge of the sources of water pollution has an effect on attitude towards water resources management. Additionally, situational factors-such as the availability of waste collection bins-influence behaviour in relation to water pollution. These findings suggest the need to deepen awareness on water pollution and to consider situational factors in policy design and implementation.
\end{abstract}

Keywords Environmental knowledge $\cdot$ Pro-environmental behaviour $\cdot$ Situational factors $\cdot$ Water pollution $\cdot$ Ghana

\section{Introduction}

Water resources contribute to development in many ways; through provision of ecosystem services, employment creation, recreational functions, among others (World Water Development Report 2015; United Nations Environment Programme 2017). Recent evidence suggests that population upsurge has increased demand for many goods and services that depend on water resources (United Nations Environment Programme 2017). In addition, unsafe use of water resources has resulted in pollution of seas, rivers, lakes, lagoons and oceans, with numerous consequences on health, economic and recreational functions of water resources (OECD 2012; United Nations World Water Assessment Programme 2015; United Nations Environment Programme 2017). Given the clear recognition that much of the sources of water pollution are anthropogenic, recent efforts to address the problem have focused on understanding and influencing behaviours

Murat Okumah

ee15sa@leeds.ac.uk

1 Sustainability Research Institute, University of Leeds, Leeds LS2 9JT, England, UK

2 Jesus College, University of Cambridge, Cambridge CB1 8BL, England, UK in relation to water pollution (Blackstock et al. 2010; OECD 2012; Okumah et al. 2019a).

Understanding and influencing individuals' behaviours in relation to water pollution requires a profound understanding of the key determinants of pro-environmental behaviour. The quest to understand the determinants of such behaviours has resulted in a plethora of research that explores, for example, whether awareness, attitudes and situational factors affect behaviour regarding water pollution (e.g., Macgregor and Warren 2006; Barnes et al. 2009; Cobbinah 2015; Okumah et al. 2018, 2019b, c). Although developing countries record the highest rate of water pollution (United Nations 2016a, b), research on the topic remains scarce within the developing country context. Further, the limited research within the developing country context typically relies on first-generation statistical techniques which often fail to address the complexities of pro-environmental behaviour. This limited understanding hinders the design of effective policies to address water pollution.

Employing an extended attitude-behaviour-context (ABC) model, we explore potential determinants of behaviours aimed at mitigating water pollution using survey data from Ghana. Ghana serves as a good case study, first, because the country is endowed with water resources, and also because water pollution is a major environmental problem (Ministry 
of Water Resources, Works and Housing [MWRWH] 2007). Specifically, we ask the following questions: does environmental knowledge, attitudes and situational factors affect behaviour regarding water resource pollution? How does this happen? To do this, we apply the conditional process modelling (CPM) technique to analyse the survey data. Using the CPM, we advance existing knowledge in at least two ways: first, unlike many existing studies in water resources management that look at the individual contributions of potential determinants such as knowledge, attitudes and situational factors, this study covers the joint contributions of these variables. Second, CPM allows us to test the mechanisms through which the different variables transmit their effect onto others, and the conditions under which this happens, which previous studies relying on correlations and multiple regressions were unable to reveal. This is expected to improve our understanding of the determinants of behaviour in relation to water pollution which could aid the design of effective policies (Jackson 2005; Steg and Vlek 2009; Okumah et al. 2019a).

The rest of the paper is structured as follows: the next section provides an overview of the theoretical model applied in the study. This is followed by a presentation of the materials and methods used. Next, the results are presented, followed by a discussion section. The final section presents our concluding remarks, highlighting future research directions and policy implications of our findings.

\section{Theoretical framework: attitude-behaviour-context model (ABC)}

Earlier models of pro-environmental behaviour have been reductionist, focusing sorely either on internal or on external determinants of behaviour (Jackson 2005, Steg and Vlek 2009). The internalist standpoint focused on factors such as attitudes, beliefs and other intrinsic motivations, while the externalist perspectives focused exclusively on external factors such as institutional constraints and/or support, cost of engaging in a behaviour, and social systems.

The internalist-externalist divide operates on the premise that human behaviour is determined exclusively by either intrinsic or extrinsic factors. This thinking is limited in at least two ways: first, the approach neglects factors from the other group-that may be crucial drivers of pro-environmental behaviour; second, the complex interaction between internal and external factors is not explored. These limitations have contributed to a lack of understanding of the determinants of pro-environmental behaviour and the complex relationship between agency and environment. It has been argued that the lack of a comprehensive model to fully predict pro-environmental behaviour contributes in part to the failure of many policies that aim at influencing behaviour (e.g., Jackson 2005). The complex nature of behaviour and environmental issues requires models that are comprehensive and multifaceted, accounting for personality issues (e.g., attitudes, values), social influences (e.g., subjective, social and moral norms), habits, personal capabilities and situational factors.

A crucial attempt was made by Stern (2000) in the 'Attitude-Behaviour-Context' model to help overcome the limitations of the internalist-externalist dichotomy. The ABC models behaviour as a multifaceted interactive outcome of internal attitudinal variables and external circumstantial elements (Stern 2000). The strength of this model lies in the acknowledgement of the complex interaction between internal and external factors. It is argued that where situational factors (e.g., monetary incentives and costs, institutional support), play a weak role, the attitude-behaviour link is strong, however, the link is non-existent or weak at best, when situational factors exert a strong influence.

There is a wealth of evidence from past empirical studies and meta-analytic reviews to support the link between attitude and behaviour in different pro-environmental behaviours. For example, Huffman et al. (2014) and Wesselink et al. (2017) found that environmental attitudes were related to sustainable waste management behaviours; for land and water quality research, Vrain et al. (2014) found that attitudes were associated with uptake of diffuse pollution mitigation measures. Some narrative reviews (e.g., Kollmuss and Agyeman 2002) and meta-analytic reviews (e.g., Bamberg and Möser 2007; Baumgart-Getz et al. 2012; Okumah et al. 2019a, b) have established the attitude-behaviour link.

After a meta-analytic review of evidence on the determinants of pro-environmental behaviour, Hines et al. (1987) concluded that pro-environmental behaviour depended largely on situational factors such as economic cost of undertaking an activity. Okumah et al. (2019a) also concluded from their systematic review that situational factors were the commonly stated moderators among other psycho-social determinants of pro-environmental behaviour in the farm context. Situational factors identified include institutional support or constraint, farm size, farm type, farm tenure, income, cost of compliance, 'goodness of fit' of schemes, flexibility of regulations, and size of buffer. This highlights the widely acknowledged role of situational factors in predicting pro-environmental behaviour. However, the complex interaction between situational factors and behaviour remains unexplored in behaviours related to water pollution.

Again, there is evidence to suggest that environmental knowledge influences environmental attitudes and behaviours. For instance, Okumah et al. (2018) observed that farmers' knowledge of diffuse pollution and best management practices significantly influenced uptake of best 
management practices. We therefore include environmental knowledge, to extend the $\mathrm{ABC}$ model.

\section{Materials and methods}

\section{Measurement instrument}

A Likert type questionnaire was designed to operationalise the model used in this study. The questionnaire contained statements that measured the variables in the model: knowledge, attitude, situational factors and behaviour. Earlier versions of the questionnaire were reviewed by senior academics. Their feedback was used to revise the questionnaire regarding the wording, structure and brevity.

The construct "knowledge" was measured by asking respondents to rate their knowledge on some (potential) causes of water pollution in Ghana. Three statements were used here: "Open defecation pollutes rivers, lakes and the sea", "Chemicals from farms pollute rivers, lakes and the sea" and "Illegal mining pollutes rivers, lakes and the sea". The responses were captured on a five-point scale: 1 (I don't know about that at all) to 5 (I know very much about that), with 1 suggesting low level of knowledge regarding the (potential) causes of water pollution in Ghana.

Attitude was conceptualized using intrinsic motivations to act pro-environmentally - in relation to water resources. This was used to evaluate the extent to which actions related to water quality improvement were positively or negatively judged by respondents. Specific statements include: "I welcome the idea of stopping illegal mining in order to reduce water pollution", "I support the cause to reduce the problem of water pollution because it has an effect on our health and other living organisms" and "I support the cause to reduce the problem of water pollution because it is bad for the environment and future generations". The scale ranged from 1 (strongly disagree) to 5 (strongly agree), with a low score pointing to weak pro-environmental attitude and a high score suggesting a strong pro-environmental attitude.

Situational factors were measured by focusing on perceptions regarding conditions that could facilitate or hinder the execution of pro-environmental behaviours. Three statements were used here: "The only way to stop illegal mining is if government gives people jobs", "I throw or drop litter at the shores of rivers, lakes and the sea if there are no waste collection bins or trash cans" and "I might consider doing what is right if state authorities keep insisting on it". The scale ranged from 1 (strongly disagree) to 5 (strongly agree), with a low score signalling a perceived low influence and a high score, a high influence of the situational factor in question.

The last construct, pro-environmental behaviour was assessed by asking respondents how often they engaged in activities that (potentially) pollute water. The responses were captured on a scale ranging from 1 (never) to 5 (always). The two statements- "I find myself throwing or dropping litter around the sea shore or river bank" and "I flush one or more of the following: cigarettes, condoms, cotton swabs, diapers, medication/drugs, needles, paper towels and/or wipes, through sinks or water closets"-were negatively worded. That is, people who are environmentally inclined are expected to score low (by selecting never) as they would not have engaged in such 'negative' practices. These scores were reverse coded: never $=5$, always $=1$. Following this, the lowest score indicated poor pro-environmental behaviour and the uppermost score suggests the best possible behaviour.

The questionnaire contained two other components: the first section captured socio-demographic information (age, gender, educational attainment, and employment status) of respondents while the last section was open ended, focussing on further comments from survey participants. The socio-demographic section was aimed at eliciting data that could help us perform further analysis. This include for instance, testing whether there are differences in responses from different age groups, educational classes and whether these factors moderate the relationships among the variables contained in the model. The open-ended section was aimed at gathering further qualitative data from respondents; this information may offer useful insights into the inferential analysis of the quantitative data.

\section{Data collection and profile of participants}

An online survey was implemented in October, 2018 to gather data from the Ghanaian public (specifically people who reside in coastal areas in Accra). Ghana is endowed with water resources - the sea, rivers and lakes - that serve multiple purposes in the country's sustainable development agenda (MWRWH 2007) (Fig. 1). Moreover, "the [water] resource is becoming increasingly scarce and often of inferior quality" (MWRWH 2007, p. 13). These concerns make water pollution a topical issue in Ghana's policy circles. The importance of water resources management is expressed in the National Water Policy document:

"...the overall goal of the National Water Policy is to achieve sustainable development, management and use of Ghana's water resources to improve health and livelihoods, reduce vulnerability while assuring good governance for present and future generations" (MWRWH 2007, p. 13).

Undeniably, the realisation of this goal depends very much on stakeholders' knowledge, attitudes, and behaviours in relation to water pollution (Okumah et al. 2020). This makes the general public an appropriate source of data 


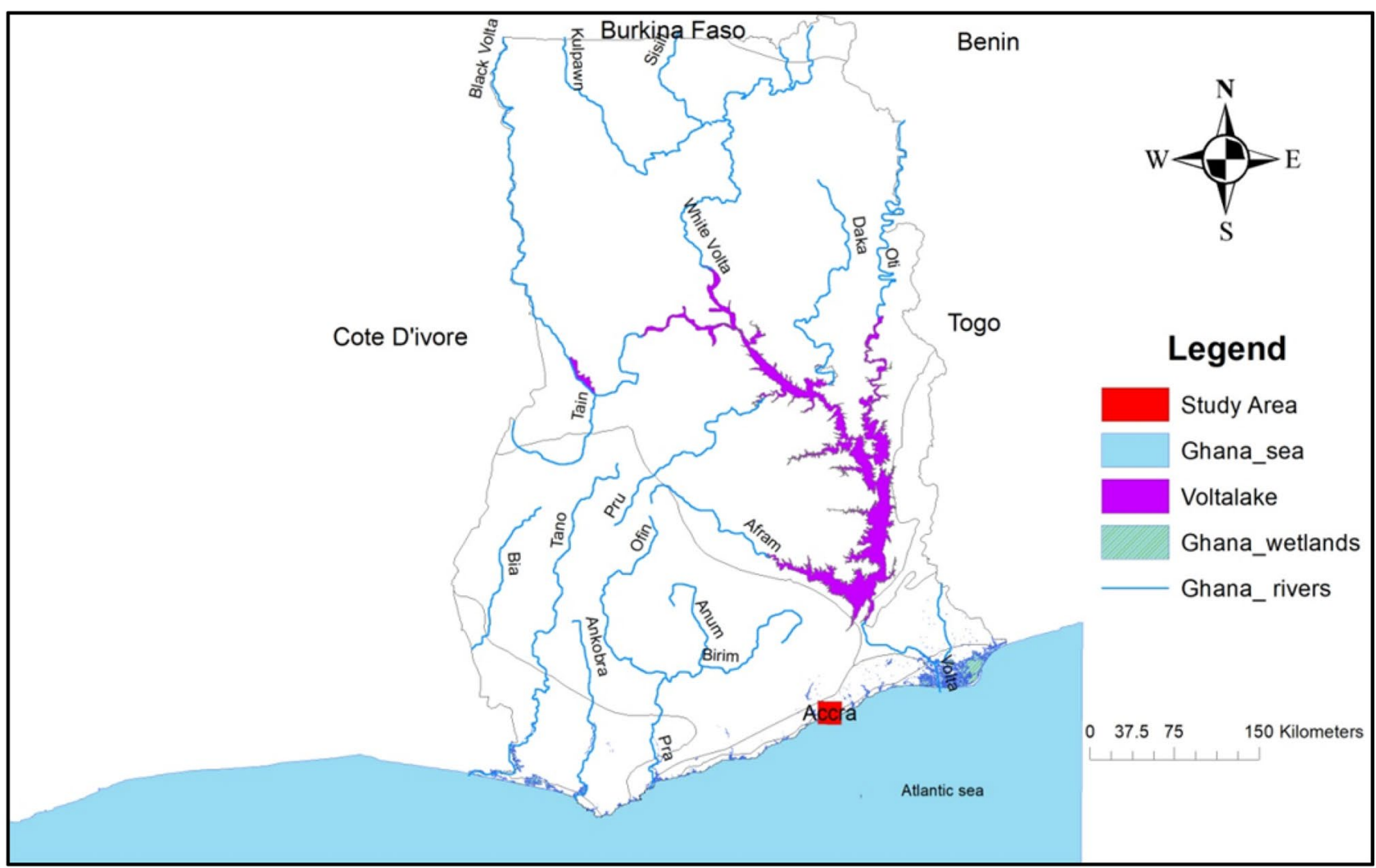

Fig. 1 Study area

for this research. People were invited via email and social media—LinkedIn, Facebook, Twitter and WhatsAppto partake in this research. Only individuals who lived in coastal communities around Accra completed the survey. Accra was selected based on a number of reasons. First, Accra is noted for waste pollution of its coastal resources due to the increasing level of urbanization (Ghana Statistical Service 2014). This puts pressure on its water resources in areas like Labadi, Jamestown, Usshertown and Tudu which share boundaries with the Gulf of Guinea. Current studies also reveal the deteriorating state of the coastal areas in the Accra Metropolis (Abraham et al. 2016). These justify the selection of Accra Metropolis and the coastal communities as the study area. Notwithstanding the relatively limited sample, this study offers valuable insights into the factors influencing pro-environmental behaviour within the water resources sector.

The survey was implemented through self-completion. The data collected amount to 281 responses. Next, we examined the data to help detect unengaged responses. Using the standard deviations of each of the responses, we found that three cases show a standard deviation of zero, suggesting non-engagement of those survey participants. We examined these cases closely after which we removed them from the dataset. Following this, only 278 cases were retained as the total number of usable responses. Table 1 provides a summary of respondents' socio-economic characteristics. The majority of respondents were males. Survey respondents

Table 1 Socio-economic characteristic of respondents

\begin{tabular}{llll}
\hline Variable & Group & $N$ & Percentage \\
\hline Gender & Male & 276 & 67.8 \\
& Female & 32.2 \\
Educational attainment & Without university & 273 & 14.3 \\
& $\quad$ degree & & \\
& With university (first) & 61.9 \\
& $\quad$ degree & & \\
& With a minimum of & & 23.8 \\
& $\quad$ a second university & & \\
Employment status & $\quad$ Unemployed & 264 & 20.0 \\
& Student & & 38.8 \\
Age & Employed & 41.7 \\
\hline
\end{tabular}

$N$ number of responses; for educational attainment, the "without university degree" category covers people with up to high school and diploma education/certificates. The second category, "first degree" refers to B.A., B.Sc., LLB, B.Com.; and the last category, "With a minimum of a second university degree" refers to M.A., M.Sc, M.Phil. and Ph.D. holders 
were relatively young (ranging from 19 to 54 years), with a median age of $26 .{ }^{1}$ About two-fifths of respondents were employed.

\section{Analytical methods}

As mentioned in "Measurement instrument", each construct contained more than one measurement item which are unidimensional (McIver and Carmines 1981, Babbie 1999). Following this, we conducted a reliability test using Cronbach's $\alpha$ to examine internal consistency among the different scale items. An $\alpha$ of at least 0.70 is deemed reliable (Cronbach 1951; Fraenkel and Wallen 2000). Data screening ended with additional investigations of multivariate normality.

A CPM technique was applied to analyse the survey data. The CPM is deemed appropriate for the present study as it allows for the exploration of the complex mechanisms through which the different constructs affect each other as well as the conditions under which such relationships operate (Hayes 2012, 2013). Additionally, the technique enables an evaluation of the validity and reliability of observed model parameter estimates, and also helps to check the possibility of confounding variables (Hayes 2012, 2013; Lomax and Schumacker 2012). We combined SPSS IBM version 24 and the lavaan package within RStudio (0.5-23.1097) to perform the CPM (Rosseel 2017).

The CPM was performed in two main phases. First, a twostage approach to Structural Equation Modelling (SEM) was applied: we analysed the measurement model for identification, reliability and validity, and later, we tested the structural paths in the model (Bagozzi and Yi 2012). The use of SEM has an advantage over first-generation statistical procedures (e.g., multiple regression) in that the technique makes it possible to take into account types of error confounding as well as methodical errors (see Bagozzi and Yi 2012). The second phase of the CPM involved multi-group analysis to identify variables that could influence the relationships being tested. These variables are referred to as moderators: factors that contingently influence the statistical significance, direction and/or strength of the relationship between two or more other variables (Hayes 2012, 2013). These variables-such as gender and educational attainment - have been mentioned to have an influence on environmental awareness, attitudes and behaviours (e.g., Ervin and Ervin 1982; Hines et al. 1987; Norris and Batie 1987; Gould et al. 1989; Kollmuss and Agyeman 2002; Mensah 2012; Acheampong 2017; Okumah et al. 2018). The multi-group technique has at least two

\footnotetext{
1 We report the median because the data was not normally distributed: (Kolmogorov-Smirnov statistic $=0.328 ; \quad d f=278 ; \quad p$ value $<0.001)$, thus making the median reliable than the mean $(26.5$; SD 4.6).
}

advantages over doing separate single-group analyses. First, it provides a test for the statistical significance of any differences revealed between groups and second, if there are no differences between groups, or if the group differences are limited to a few model parameters, the simultaneous analysis of groups provides more accurate parameter estimates than would be obtained from two separate single-group analyses-thus, increasing the statistical power of the analysis (Hayes 2012, 2013; Rosseel 2017).

\section{Results}

\section{Overview of survey responses}

The descriptive statistics of all constructs are presented in Table 2. All constructs had a high mean score, between 2.97 (for situational factors) and 4.87 (for attitude). This suggests that the environmental knowledge, attitude and behaviour of survey participants are high; suggestive of an environmentally inclined sample. Results of Cronbach's $\alpha^{2}$ show good reliability with the exception of situational factors which fall the value falls well below the recommended threshold of 0.7 .

\section{Assessing the measurement model}

The measurement model was assessed using confirmatory factor analysis. The model (Fig. 2) specifies how the observed variables (in rectangles) depend on the unobserved or latent variables (in ellipses). For instance, outcomes for the observed variables "Attitude 1", "Attitude 2" and "Attitude 3"- "I welcome the idea of stopping illegal mining in order to reduce water pollution", and "I support the cause to reduce the problem of water pollution because it is bad for the environment and future generations" respectively-are hypothesized to depend on the single underlying, but not directly observed variable, attitude. This is applicable to all other variables in Fig. 2.

To assess the fit of the measurement model, we used a range of incremental and absolute indices as different indices reflect diverse aspects of model fit (Hu and Bentler 1999; Brown 2006; Hooper et al. 2008). Results indicate a good fit: $\chi^{2}(n=278, d f=32)=50.3, p<0.05$; comparative fit index $(\mathrm{CFI})=0.987$; Tucker - Lewis index $(\mathrm{TLI})=0.982$; root mean square error of approximation $($ RMSEA $)=0.045$; standardized root mean square residual $(\mathrm{SRMR})=0.063$ (see Table 3). This suggests that the measurement model is supported by the data. From Table 4, factor loadings for

\footnotetext{
${ }^{2}$ Pro-environmental behaviour is a formative scale that was measured by factual statements and not perceptual questions. Cronbach's $\alpha$ is thus not needed for this construct.
} 
Table 2 Descriptive results of Respondents' evaluation of survey item $(n=278)$

\begin{tabular}{|c|c|c|c|c|}
\hline Construct & Items & Mean & $\begin{array}{l}\text { Standard } \\
\text { deviation }\end{array}$ & Cronbach's $\alpha$ \\
\hline \multirow[t]{5}{*}{ Knowledge } & - & 4.48 & 0.78 & 0.79 \\
\hline & Open defecation pollutes rivers, lakes and the sea & 4.72 & 0.83 & - \\
\hline & Chemicals from farms pollute rivers, lakes and the sea & 4.61 & 0.88 & - \\
\hline & Illegal mining pollutes rivers, lakes and the sea & 4.74 & 0.86 & - \\
\hline & $\begin{array}{l}\text { Flushing one or more of the following: cigarettes, condoms, cotton swabs, diapers, medi- } \\
\text { cation/drugs, needles, paper towels and/or wipes, through sinks or water closets pollutes } \\
\text { rivers, lakes and the sea }\end{array}$ & 3.85 & 1.34 & - \\
\hline \multirow[t]{4}{*}{ Attitude } & - & 4.87 & 0.47 & 0.87 \\
\hline & I welcome the idea of stopping illegal mining in order to reduce water pollution. & 4.80 & 0.62 & - \\
\hline & $\begin{array}{l}\text { I support the cause to reduce the problem of water pollution because it has an effect on our } \\
\text { health and other living organisms }\end{array}$ & 4.90 & 0.49 & - \\
\hline & $\begin{array}{l}\text { I support the cause to reduce the problem of water pollution because it is bad for the envi- } \\
\text { ronment and future generations }\end{array}$ & 4.91 & 0.47 & - \\
\hline \multirow[t]{3}{*}{ Behaviour } & - & 4.57 & 0.60 & - \\
\hline & I find myself throwing or dropping litter around the sea shore or river bank & 4.67 & 0.67 & - \\
\hline & $\begin{array}{l}\text { I flush one or more of the following: cigarettes, condoms, cotton swabs, diapers, medica- } \\
\text { tion/drugs, needles, paper towels and/or wipes, through sinks or water closets }\end{array}$ & 4.48 & 0.90 & - \\
\hline \multirow[t]{4}{*}{ Situational factors } & - & 2.97 & 0.85 & 0.30 \\
\hline & I might consider doing what is right if state authorities keep insisting on it & 4.00 & 1.34 & - \\
\hline & $\begin{array}{l}\text { I throw or drop litter at the shores of rivers, lakes and the sea if there are no waste collec- } \\
\text { tion bins or trash cans }\end{array}$ & 1.68 & 1.20 & - \\
\hline & The only way to stop illegal mining is if government gives people jobs & 3.21 & 1.41 & - \\
\hline
\end{tabular}

indicator variables are mostly high, demonstrating that the measurement model is satisfactory (Stevens 2009).

Next, we used squared multiple correlations (SMC) (Boomsma 2000) as a measure of reliability. These show the contributions of each of the indictors to their respective latent constructs. Values range between 0 and 1 , with higher values indicative of a good measure. From Table 4, SMC values range from 0.19 to 0.78 for knowledge variables; $0.42-0.97$ for attitudinal variables; $0.09-0.33$ for situational factors. Overall, attitudinal variables appear to be the best indicators of the latent constructs, while situational factors performed quite poorly. Again, latent variables are poorly associated, with correlations well below the threshold of 0.80 (Table 4)-signifying that discriminant validity is unlikely to be a problem in the present study.

\section{Path analysis: specifying and testing the structural model}

The structural model [see Fig. 3 for a simplified version] links knowledge to attitude and behaviour. Situational factors are hypothesized to affect behaviour. Therefore, while attitude and situational factors are hypothesized to directly affect behaviour, the effect of knowledge on behaviour is indirect—-through attitude.
An evaluation of the structural model indicates a satisfactory fit: $\chi^{2}(n=278, d f=50)=248.9, p<0.01$; comparative fit index $(\mathrm{CFI})=0.982$; Tucker-Lewis index $(\mathrm{TLI})=0.976$; Root mean square error of approximation (RMSEA) $=0.047$; $\mathrm{SRMR}=0.059$ (Table 3 ). From Table 5, the path from knowledge to attitude was statistically significant $(p<0.001)$, with knowledge accounting for approximately $40 \%$ of the variance in attitude. The standardised regression co-efficient of 0.795 for the knowledge-attitude link implies that for every unit increase in a respondent's knowledge, attitude towards water pollution prevention improved by approximately 0.80 units. Indeed some respondents left comments highlighting the role of environmental knowledge, and have called for further education on water pollution. For example, some respondents indicated that:

“...people don't know the effect of these chemicals on health", "there should be massive mass education concerning water pollution because water is life", "most Ghanaians need education about water pollution" (see "Appendix").

Results further indicate that the indirect effect of knowledge on behaviour is 0.1 ; however, this was not statistically significant $(p>0.05)$. Thus, although knowledge directly predicts attitude, there was no evidence to support the 


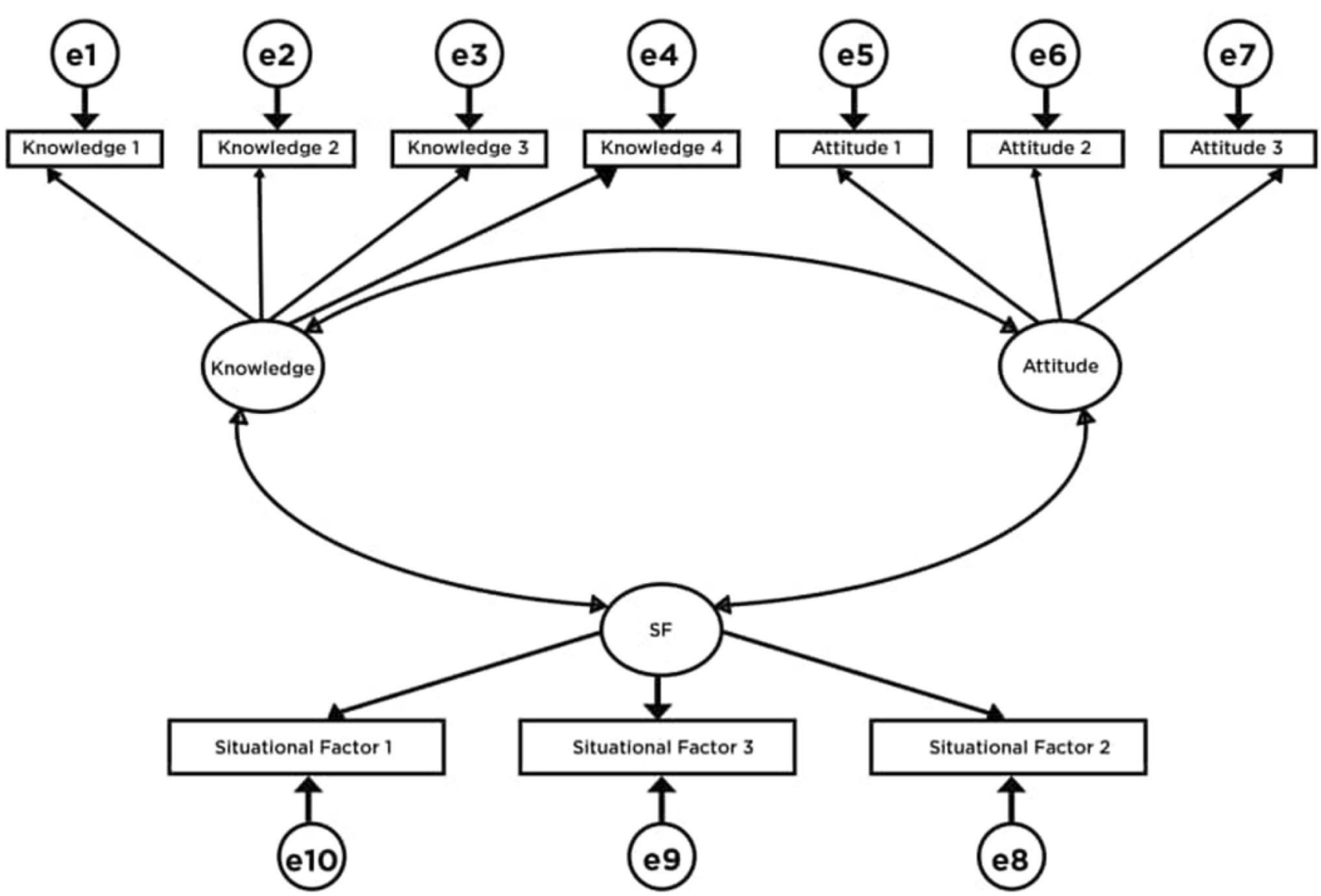

Fig. 2 The measurement model. $S F$ situational factors, $e$ unobserved errors terms. Refer to Table 2 for meaning of observed variables (contained in rectangles)

Table 3 Model fit indices

\begin{tabular}{|c|c|c|c|c|c|c|c|c|}
\hline$N$ & $\chi^{2}$ & $\begin{array}{l}\text { Degrees of } \\
\text { freedom }(d f)\end{array}$ & $p$ value & CFI & TLI & RMSEA & 90\% conf. int. (RMSEA) & SRMR \\
\hline \multicolumn{9}{|c|}{ Measurement model } \\
\hline 278 & 50.3 & 32 & 0.021 & 0.987 & 0.982 & 0.045 & $0.018,0.068$ & 0.063 \\
\hline \multicolumn{9}{|c|}{ Structural model } \\
\hline 278 & 248.9 & 42 & 0.007 & 0.982 & 0.976 & 0.047 & $0.025,0.067$ & 0.059 \\
\hline \multicolumn{9}{|c|}{ Structural model (multi-group) } \\
\hline 278 & 5657.6 & 106 & 0.000 & 0.000 & -0.827 & 0.422 & $0.408,0.435$ & 61.776 \\
\hline
\end{tabular}

hypothesis that knowledge of the sources of water pollution indirectly affect behaviour in relation to water pollution.

Results also show that situational factors (e.g., the availability of dustbins) directly affect behaviour $(p<0.1)$, with situational factors accounting for less than $10 \%$ of the variation in behaviour (Table 5). A regression coefficient of -0.581 suggests that for every unit increase in a respondent's perceived influence of situational factors on behaviour, their likelihood of engaging in pro-environmental behaviour reduced by 0.56 units. The implication is that people who give a high explanatory power to situational factors such as the lack of dustbins were more likely to litter indiscriminately around water resources. Some comments from survey participants were in line with this finding (see examples below).

"Government must implement its policies; [providing] dustbins...to enable us act right", "rules and regulations should [be] enforced and acted upon to keep people on their toes" (“Appendix").

All other paths - attitude-behaviour, and knowledgebehaviour links - were non-significant $(p>0.05)$ although 
Table 4 Results for measurement model (Fig. 2)

\begin{tabular}{llllll}
\hline Observed variables & Latent variables & $\begin{array}{l}\text { Standardized } \\
\text { estimate }\end{array}$ & Std. err & $p$ value & $\begin{array}{l}\text { Squared } \\
\text { multiple cor- } \\
\text { relation }\end{array}$ \\
\hline Knowledge 1 & Knowledge & 0.735 & 0.041 & $0.000^{* * *}$ & 0.781 \\
Knowledge 2 & Knowledge & 0.693 & 0.046 & $0.000^{* * *}$ & 0.623 \\
Knowledge 3 & Knowledge & 0.740 & 0.043 & $0.000^{* * *}$ & 0.746 \\
Knowledge 4 & Knowledge & 0.589 & 0.080 & $0.000^{* * *}$ & 0.193 \\
Attitude 1 & Attitude & 0.402 & 0.033 & $0.000^{* * *}$ & 0.421 \\
Attitude 2 & Attitude & 0.465 & 0.022 & $0.000^{* * *}$ & 0.906 \\
Attitude 3 & Attitude & 0.462 & 0.021 & $0.000^{* * *}$ & 0.972 \\
Situational factor 1 & Situational factors & 0.766 & 0.253 & $0.002 * * *$ & 0.326 \\
Situational factor 2 & Situational factors & 0.181 & 0.116 & 0.118 & 0.023 \\
Situational factor 3 & Situational factors & 0.427 & 0.162 & $0.009 * * *$ & 0.092 \\
Covariances & & & & & \\
Knowledge & Attitude & 0.622 & 0.041 & $0.000^{* * *}$ & - \\
Knowledge & Situational factors & 0.130 & 0.106 & 0.219 & - \\
Attitude & Situational factors & 0.290 & 0.112 & $0.009 * * *$ & - \\
\hline
\end{tabular}

Refer to Table 2 for meaning of the respective observed variables (e.g., K1, K2, etc.)

$* * * p$ value $<0.01, * * p$ value $<0.05, * p$ value $<0.1$

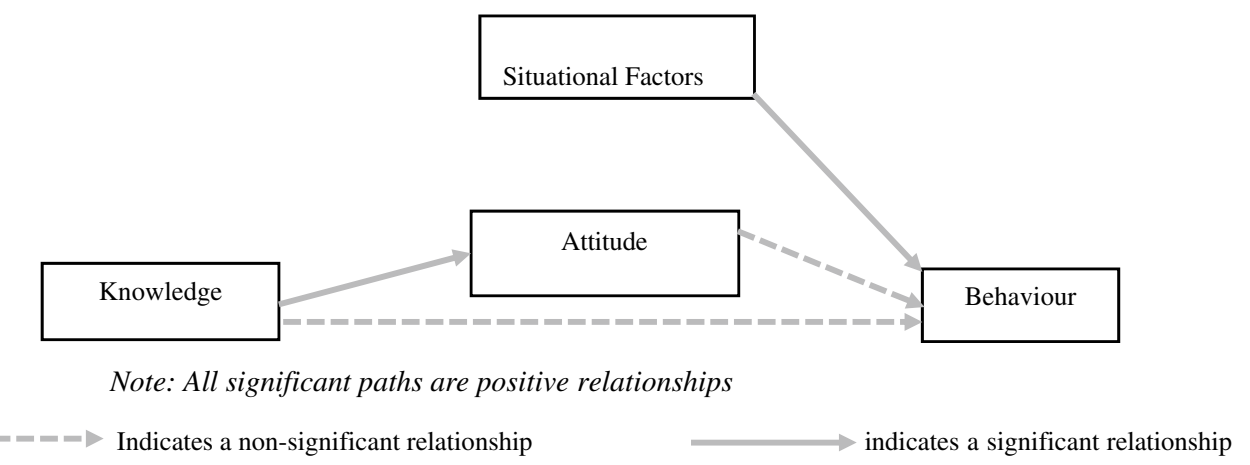

Fig. 3 Final structural model testing the knowledge-attitudebehaviour-context links status, respectively. Scores for situational factors were also recoded: values from the median upwards $=1$; values below median $=2$ (median value $=3.0)$. Output from $\mathrm{R}$ indicated that the model was unidentified due to limited samples for various groups. The model was identified following additional constrains to some model parameters, however, model indices indicate a poor fit (see Table 3 ).

\section{Discussion}

Using an extended $\mathrm{ABC}$ model, the aim of the study was to test whether and how environmental knowledge, attitudes and situational factors affect behaviours regarding water pollution. There are a few limitations to clarify before moving on to discuss our results. For instance, the survey approach used in this study is prone to limited sampling given that some people are less likely to have access to internet, and also because people who are not literate in English language 
Table 5 Results for the structural model (Fig. 3)

\begin{tabular}{llcccc}
\hline Observed variables & Latent variables & $\begin{array}{l}\text { Standardized } \\
\text { estimate }\end{array}$ & Std. err & $p$ value & $\begin{array}{l}\text { Squared } \\
\text { multiple cor- } \\
\text { relation }\end{array}$ \\
\hline Knowledge 1 & Knowledge & 0.735 & 0.041 & $0.000^{* * *}$ & 0.781 \\
Knowledge 2 & Knowledge & 0.693 & 0.046 & $0.000^{* * *}$ & 0.624 \\
Knowledge 3 & Knowledge & 0.739 & 0.043 & $0.000^{* * *}$ & 0.746 \\
Knowledge 4 & Knowledge & 0.590 & 0.080 & $0.000^{* * *}$ & 0.193 \\
Attitude 1 & Attitude & 0.315 & 0.027 & $0.000^{* * *}$ & 0.422 \\
Attitude 2 & Attitude & 0.365 & 0.018 & $0.000^{* * *}$ & 0.910 \\
Attitude 3 & Attitude & 0.361 & 0.018 & $0.000^{* * *}$ & 0.968 \\
Situational factors 1 & Situational factors & 0.178 & 0.127 & 0.159 & 0.018 \\
Situational factors 2 & Situational factors & 0.976 & 0.497 & $0.050^{*}$ & 0.669 \\
Situational factors 3 & Situational factors & 0.209 & 0.140 & 0.135 & 0.022 \\
Behaviour 1 & Behaviour & 0.297 & 0.134 & $0.026 * *$ & 0.266 \\
Behaviour 2 & Behaviour & 0.208 & 0.088 & $0.018^{*}$ & 0.072 \\
Path analysis: effects of & latent variables on other latent variables & & \\
Knowledge & Attitude & 0.795 & 0.086 & $0.000^{* * * *}$ & 0.387 \\
Knowledge & Behaviour & 0.022 & 0.172 & 0.899 & - \\
Attitude & Behaviour & 0.034 & 0.028 & 0.218 & - \\
Situational factors & Behaviour & -0.581 & 0.083 & $0.067 *$ & 0.071 \\
\hline Refer & & & &
\end{tabular}

Refer to Table 2 for meaning of the respective observed variables (e.g. K1, K2, K3, etc.). Standardised indirect effect of knowledge on behaviour $=0.1 ; p>0.05$, *** $p$ value $<0.01,{ }^{*} p$ value $<0.05, * p$ value $<0.1$

are excluded. ${ }^{3}$ Of course, relying on the views of only people who are literate in English Language excludes those of non-literate people who form a significant proportion of the population, whose environmental knowledge, attitudes and behaviours impact water resources (MWRWH 2007; Ghana Statistical Service 2013). This partial view could limit our understanding of the complex drivers of behaviours across the entire population.

Again, while self-reported studies have been well established in various fields including environmental psychology and water resources management, they are not without limitations. Evidence suggests that survey participants are likely to over-report their pro-environmental behaviour, with social desirability and memory bias being common causes of such exaggerations (Warriner et al. 1984; Barr 2007; Kormos and Gifford 2014). Nonetheless, a recent meta-analysis of the literature found that self-reported measures of proenvironmental behaviour were strongly positively related to objective measures (Kormos and Gifford 2014).

Beyond these limitations, the study offers useful findings which we discuss as follows. We found evidence to support

\footnotetext{
3 This limitation is noteworthy in the Ghanaian context where the population without internet access and those who are not literature in English language are quite substantial (Ghana Statistical Service 2013). Internet usage data are estimates for 2018: https://www.graph ic.com.gh/news/general-news/over-10-million-ghanaians-using-theinternet-report.html.
}

the hypothesis that environmental knowledge affects environmental attitudes, and knowledge appears to be a good predictor of the latter. This is in line with the findings of Hadrich and Van Winkle (2013), Drangert et al. (2017) and Ulrich-Schad et al. (2017) who found that knowledge of environmental problem and action strategies has an influence on environmental attitudes and uptake of measures to improve water quality. Indeed, people's attitudes may be determined by their knowledge of the environmental problem and/or mechanisms to reduce the problem in question (Kollmuss and Agyeman 2002). The acquisition and assimilation of environmental management information improves environmental consciousness, boost their locus of control and may lead to the development of favourable environmental attitudes (Kollmuss and Agyeman 2002; Lobley et al. 2013). This perhaps, explains why environmental knowledge appears to be a necessary but insufficient condition for encouraging positive environmental attitudes (Kollmuss and Agyeman 2002; Bamberg and Möser 2007; Steg and Vlek 2009; Blackstock et al. 2010).

It must be noted, however, that some studies have concluded that despite widespread knowledge of environmental management schemes, negative environmental attitudes were observed among stakeholders (e.g., Macgregor and Warren 2006; Barnes et al. 2009). They attribute this to situational factors such as the inflexible nature of some environmental management schemes, lack of institutional support and high cost of compliance. Again, the influence of environmental 
knowledge on attitudes may be moderated by the characteristics of the information and the context: credibility of the sender, message framing, receptiveness of the audience, and capacity of recipients to apply the information (Hovland et al. 1953; Juntti and Potter 2002; O' Keefe 2002; Silgo and Massey 2007; Vrain and Lovett 2016). The role of these mediators and moderators affect the link between environmental knowledge and attitudes and may explain why we found a modest direct link between the two variables. Therefore, while awareness creation may be useful in encouraging positive environmental attitudes, the influential role of intervening factors needs to be factored into water management policies (Macgregor and Warren 2006; Barnes et al. 2009; Amponsah et al. 2016).

We do not find evidence to support the relationship between environmental attitudes and behaviour. This link may be mediated by intrinsic factors such as self-efficacy and behavioural intentions, and moderated by situational factors (Ajzen and Fishbein 1980; Hines et al. 1987; Ajzen 1991; Ajzen 2002)—but these are not explored in the present study. This finding may also be due to lack of variation in data.

We also found that situational factors have an effect on behaviour. The effect of situational factors on pro-environmental behaviour has long been established in the literature (e.g., Hines et al. 1987; Stern 2000; Kollmuss and Agyeman 2002; Steg and Vlek 2009; Barnes et al. 2009; Amponsah et al. 2016; Acheampong 2017; Okumah et al. 2018). For instance, in a recent study in Ghana, Amponsah et al. (2016) concluded that despite vegetable farmers' awareness of the World Health Organization's farm-based multiple-barrier approach, their compliance was hindered by cost of adopting those practices. As discovered in this study, situational factors such availability of institutional support have a tendency to influence people's behaviours regarding water resources. Of course, the lack of the needed facilities (e.g., waste collection bins ${ }^{4}$ ) may impede uptake of pro-environmental behaviour even when people have positive attitudes and intentions (Blake 1999). Blake attributes this to a number of factors: (1) ascription of responsibility-some people feel they should not take responsibility for pro-environmental behaviours because government ought to have provided the necessary conditions for undertaking the prescribed behaviours; (2) a lack of trust in institutions often discourages people from behaving pro-environmentally; (3) a lack of time (Blake 1999, see also Kollmuss and Agyeman 2002; Jackson 2005; Steg and Vlek 2009). This may explain why, for instance, unavailability of waste collection bins near

\footnotetext{
${ }^{4}$ We emphasise lack of waste collection bins near water resources as it was the only indicator of the situational factors that had a statistically significant effect on the latent variable (see Table 5).
}

water resources is likely to have an influence on whether people litter indiscriminately or not.

Further, our results suggest that situational factors have a low direct explanatory power on behaviours-properly disposing waste. Stated differently, the direct link between situational factors and behaviour was found to be weak as situational factors account for only $7 \%$ of the variation in behaviour. This finding may be due to the complex dynamic ways in which situational factors interact with behaviour (Steg and Vlek 2009). First, the relationship between situational factors and behaviour may be mediated by motivational factors, perceived and actual behavioural control (or self-efficacy) and behavioural intentions (Bandura 1977; Hines et al. 1987, Ajzen 2002; Kollmuss and Agyeman 2002). For instance, the introduction or availability of waste collection bins near water resources may trigger positive attitudes towards responsible waste disposal because it is more convenient; such positive attitudes may lead to uptake of responsible waste disposal practices. Second, situational factors may moderate the link between attitudes and behaviour (Stern 2000; Jackson 2005; Steg and Vlek 2009). For instance, while the provision of dustbins is likely to trigger positive attitudes, whether positive attitudes translate into proper waste disposal practices depends on whether people are environmentally concerned or not (Kollmuss and Agyeman 2002; Steg and Vlek 2009). The latent role of these mediators and moderators may explain why the direct link between situational factors and pro-environmental behaviour is weak at best.

Furthermore, while our results indicate the significance of situational factors in predicting pro-environmental behaviour (and adds a layer of complexity to existing knowledge), we were unable to fully demonstrate the interaction between the two. According to Blake (1999), situational factors have an influence on whether people think they are capable of behaving pro-environmentally or not, as these factors may be viewed as barriers or facilitators to the performance of a behaviour (Ajzen 2002). Understanding the complex interaction between situational factors and behaviour will provide insights into which motivational and contextual factors to focus on and when and how to combine them effectively (Jackson 2005; Steg and Vlek 2009; Van Riper et al. 2018). For instance, when and how best do we combine enforcement of regulations with education on safe methods of mining? How do these interact with people's economic, socio-political and cultural motivations? Further research on these complex interactions is urgently needed.

Although we aimed to test for potential moderators such as age, employment status, gender and educational status, we were unable to do this due to limited sample size. This limits our understanding of the determinants of pro-environmental behaviour given that the relationships being tested 
may depend on some moderators (Steg and Vlek 2009; Mensah 2012; Cobbinah 2015; Okumah et al. 2018). Different groups may have varying rational for engaging in certain practices, which may also depend on identity, socio-cultural, political and economic factors (Kollmuss and Agyeman 2002; Carfora et al. 2017). For instance, Mensah (2012) found that among international tourists in Ghana, women reported greater pro-environmental behaviour than men.

\section{Conclusion}

Given that much of the causes of the water resource pollution problem is of a behavioural nature, understanding pro-environmental behaviour as well as the determinants of such behaviours is key to designing effective policies aimed at addressing the problem. The limited studies that attempt to explore the determinants of water related proenvironmental behaviours rely typically on first-generation statistical procedures, often failing to address the complexities of pro-environmental behaviour. We advance our understanding of the determinants of pro-environmental behaviour by applying the CPM technique to analyse survey data from Ghana-using an extended ABC model. Overall, we do not find evidence supporting all paths hypothesized in the framework. Results show that knowledge of the sources of water pollution has an effect on people's attitude towards water resources pollution. Also, situational factors-such as the availability of waste collection bins near water resources influence people's behaviour in relation to water pollution. These findings suggest the need to deepen awareness on water pollution and to incorporate situational factors in policy designs.

The lack of evidence to support some relationships and the low explanatory power of situational factors suggest the need to include potential mediators such as ascription of responsibility, norms, self-efficacy and behavioural intentions, and to test for potential moderators such as gender, education and age. Including these variables in analysis could provide an improved understanding which may help tailor interventions to the motivations, capacities and circumstances of different target groups and could help maximise the benefits of interventions designed to promote proenvironmental behaviour and safeguard the quality of water resources. This requires developing extended integrative models of pro-environmental behaviour and applying multivariate statistical techniques. This could be complemented with qualitative data to provide deep insights into the drivers of pro-environmental behaviour.

Acknowledgements Authors are grateful to Abdul-Wadudu Adam Mohammed, Rachel Palfrey and Vivian Yeboah for their valuable feedback on an earlier version of the paper. Many thanks to Priscilla
Animah Owusu for her support in implementing the survey. This research did not receive any specific grant from funding agencies in the public, commercial, or not-for-profit sectors.

\section{Compliance with ethical standards}

Conflict of interest The authors declare they have no competing interests.

Open Access This article is licensed under a Creative Commons Attribution 4.0 International License, which permits use, sharing, adaptation, distribution and reproduction in any medium or format, as long as you give appropriate credit to the original author(s) and the source, provide a link to the Creative Commons licence, and indicate if changes were made. The images or other third party material in this article are included in the article's Creative Commons licence, unless indicated otherwise in a credit line to the material. If material is not included in the article's Creative Commons licence and your intended use is not permitted by statutory regulation or exceeds the permitted use, you will need to obtain permission directly from the copyright holder. To view a copy of this licence, visit http://creativecommons.org/licenses/by/4.0/.

\section{Appendix: Summary of comments from survey participants}

\begin{tabular}{ll}
\hline Variable & Comment \\
\hline Knowledge & $\begin{array}{c}\text { Education at all levels should be given to citizens in the } \\
\text { need to promote ensuring clean and quality environ- } \\
\text { mental protection practices around and on our water } \\
\text { bodies } \\
\text { Water pollution campaign must be intensified } \\
\text { It is not about getting them job. People do not know the } \\
\text { effect of these chemicals on health } \\
\text { Educating the general public would help reduce water } \\
\text { pollution and unbiased laws should be enacted so that } \\
\text { people can be penalized to serve as deterrent to others } \\
\text { Illegal mining is a multi-faceted problem that does } \\
\text { not only require job creation but education and law } \\
\text { enforcement as well } \\
\text { The need to engage in massive awareness campaign } \\
\text { and enforcement of our sanitary and environmental } \\
\text { regulations are key ways to maintain the quality of } \\
\text { water resources. } \\
\text { There should be massive mass education concerning } \\
\text { water pollution because water is life } \\
\text { Most Ghanaians need education about water pollution } \\
\text { The public must be educated on the effects of destroy- } \\
\text { ing our water bodies } \\
\text { Educating people on the preservation of our water bod- } \\
\text { ies will help reduce this problem } \\
\text { I opine the government must stress on mass education } \\
\text { on water pollution and its effects on the individual and } \\
\text { environment } \\
\text { The problem of water pollution arises as a result of } \\
\text { people not being aware of the essence of water being } \\
\text { most precious and a scare resource for the sustainabil- } \\
\text { ity of human life }\end{array}$ \\
\hline
\end{tabular}




\section{Variable Comment}

Educating and providing foreign and local internship opportunities to illegal miners

It is expedient to educate citizens on the need to keep our environment clean, dispose waste appropriately and also enforce law on environmental regulations to prevent others from being recalcitrant

The public must be educated on the effects of destroying our water bodies

It will be best if the citizenry is educated much on the need not to pollute the environment. It is the psyche that should be worked on more

I think the issue is when jobs are created, the probability people doing illegal mining will be less and the government must also increase the awareness of the dangers pollution brings to us through public education

A strategy must be developed to curb ignorance and help to redirect minds that are not resistant to change

More education is needed on the topic

Attitude Attitude is one key factor that causes water resource pollution

Reducing water pollution in Ghana has more to do with attitudinal change. Thank you

Our institutions must work by continuous enactment of laws concerning water protection and also hammer on attitudinal change by the public

Central to any protection rests on the individuals and they are expected to have positive minds and thoughts on the water bodies and the natural environment in general to ensure sustainable environmental development

Pollution and sanitation to me are both controlled by the mindsets of the people of which water pollution is no exception

Water pollution is an attitudinal problem

The problem is attitudinal

Situational Government must implement its policies. Dust bins, factors cleaning of water bodies to let us act

Illegal mining is a multi-faceted problem that does not only require job creation but education and law enforcement as well

Enforcing the law on legal/illegal mining Investing mining resources into other local industries/ firms to expand and boost employment opportunities for illegal miners

It boils down to law enforcement

It is expedient to educate citizens on the need to keep our environment clean, dispose waste appropriately and also enforce law on environmental regulations to prevent others from being recalcitrant.

Strict law enforcement must be implemented

Rules and regulations should enforced and acted upon to keep people on their toes

Behaviour Attitude, behaviour and level of knowledge have impact on water pollution

\section{References}

Abraham EM, Martin A, Cofie O (2016) Perceptions, attitudes and behaviours toward urban surface water quality in Accra, Ghana. Manag Environ Qual 27(5):491-506. https://doi.org/10.1108/ meq-07-2015-0122

Acheampong RA (2017) Towards sustainable urban transportation in ghana: exploring adults' intention to adopt cycling to work using theory of planned behaviour and structural equation modelling. Transp Dev Econ 3(8):1-11. https://doi.org/10.1007/s4089 0-017-0047-8

Ajzen I (1991) The theory of planned behavior. Organ Behav Hum Decis Process 50:179-211

Ajzen I (2002) Perceived behavioral control, self-efficacy, locus of control, and the theory of planned behavior. J Appl Soc Psychol 32:665-683

Ajzen I, Fishbein M (1980) Understanding attitudes and predicting social behaviour. Prentice-Hall Inc., Englewood Cliffs

Amponsah O, Hakan V, Schou TW, Braimah I, Abaidoo RC (2016) The impact of farmers' participation in field trials in creating awareness and stimulating compliance with the World Health Organization's farm-based multiple-barrier approach. Environ Dev Sustain 18:1059-1079

Babbie E (1999) The basics of social research. Wadsworth, New York

Bagozzi RP, Yi Y (2012) Specification, evaluation, and interpretation of structural equation models. J Acad Market Sci 40(1):8-34

Bamberg S, Möser G (2007) Twenty years after Hines, Hungerford, and Tomera: a new meta-analysis of psycho-social determinants of pro-environmental behaviour. J Environ Psychol 27:14-25

Bandura A (1977) Social learning theory. Prentice Hall, Englewood Cliffs

Barnes AP, Willock J, Hall C, Toma L (2009) Farmer perspectives and practices regarding water pollution control programmes in Scotland. Agric Water Manag 96(1):1715-1722

Barr S (2007) Factors influencing environmental attitudes and behaviours: a U.K. case study of household waste management. Environ Behav 39:435-473

Baumgart-Getz A, Prokopy LS, Floress K (2012) Why farmers adopt best management practice in the United States: a meta-analysis of the adoption literature. J Environ Manag 96:17-25

Blackstock KL, Ingram J, Burton R, Brown KM, Slee B (2010) Understanding and influencing behaviour change by farmers to improve water quality. Sci Total Environ 408:5631-5638

Blake J (1999) Overcoming the 'value-action gap' in environmental policy: tensions between national policy and local experience. Local Environ 4(3):257-278

Boomsma A (2000) Reporting analyses of covariance structures. Struct Equ Model 7(3):461-483. https://doi.org/10.1207/S15328007S EM0703_6

Brown TA (2006) Confirmatory factor analysis for applied research. The Guildford Press, New York, London

Carfora V, Caso D, Sparks P, Conner M (2017) Moderating effects of pro-environmental self-identity on pro-environmental intentions and behaviour: a multi-behaviour study. J Environ Psychol 53:92-99

Cobbinah PB (2015) Local attitudes towards natural resources management in rural Ghana. Manag Environ Qual 26(3):423-436. https ://doi.org/10.1108/MEQ-04-2014-0061

Cronbach LJ (1951) Coefficient alpha and internal structure of tests. Psychometrika 16(3):297-334

Drangert JO, Kiełbasa B, Ulen B, Tonderski KS, Tonderski A (2017) Generating applicable environmental knowledge among farmers: experiences from two regions in Poland. Agroecol Sustain Food Syst 41(6):671-690 
Ervin CA, Ervin DE (1982) Factors affecting the use of soil conservation practices: hypotheses, evidence, and policy implications. Land Econ 58(3):277-292

Fraenkel JR, Wallen NE (2000) How to design and evaluate research in education. McGraw-Hill, New York

Ghana Statistical Service (2013) Ghana statistical service 2010 population and housing census: national analytical report Ghana Statistical Service. GSS, Accra

Ghana Statistical Service (2014) 2010 population and housing census report. Ghana Statistical Service

Gould BW, Saupe WE, Klemme RM (1989) Conservation tillage: the role of farm and operator characteristics and the perception of soil erosion. Land Econ 65(2):167-182

Hadrich JC, Van Winkle A (2013) Awareness and pro-active adoption of surface water BMPs. J Environ Manage 127:221-227

Hayes AF (2012) Process: a versatile computational tool for observed variable mediation, moderation, and conditional process modelling [white paper]

Hayes AF (2013) Introduction to mediation, moderation and conditional process analysis. The Guildford Press, New York

Hines JM, Hungerford HR, Tomera AN (1987) Analysis and synthesis of research on responsible environmental behaviour: a metaanalysis. J Environ Educ 18(2):1-8

Hooper D, Coughlan J, Mullen MR (2008) Structural equation modelling: guidelines for determining model tit. Electron J Bus Res Methods 6(1):53-60

Hovland C, Janis I, Kelley H (1953) Communication and persuasion: psychological studies of opinion change. Yale University Press, New Haven

Hu L, Bentler PM (1999) Cutoff criteria for fit indexes in covariance structure analysis: conventional criteria versus new alternatives. Struct Equ Model 6(1):1-55

Huffman AH, Van Der Werff BR, Henning JB, Watrous-Rodriguez K (2014) When do recycling attitudes predict recycling? An investigation of self-reported versus observed behavior. J Environ Psychol 38:262-270

Jackson T (2005) Motivating sustainable consumption: a review of evidence on consumer behaviour and behavioural change. Sustain Dev Res Netw. http://citeseerx.ist.psu.edu/viewdoc/download?do $\mathrm{i}=10.1 \cdot 1.337 .433 \& \mathrm{rep}=\mathrm{rep} 1 \&$ type $=\mathrm{pdf}$

Juntti M, Potter C (2002) Interpreting and reinterpreting agric-environmental policy: communication, trust and knowledge in the implementation process. Sociologia Ruralis 42:216-232

Kollmuss A, Agyeman J (2002) Mind the gap: why do people act environmentally and what are the barriers to pro-environmental behavior? Environ Educ Res 8:239-260

Kormos C, Gifford R (2014) The validity of self-report measures of proenvironmental behavior: a meta-analytic review. J Environ Psychol 40:359-371

Lobley M, Saratsi E, Winter M, Bullock J (2013) Training farmers in agri-environmental management: the case of environmental stewardship in lowland England. Int J Agric Manag 3(1):12-20

Lomax RG, Schumacker RE (2012) A beginner's guide to structural equation modelling. Routledge Academic, New York

Macgregor CJ, Warren CR (2006) Adopting sustainable farm management practices within a nitrate vulnerable zone in Scotland: the view from the farm. Agric Ecosyst Environ 113:108-119

Mciver JP, Carmines EG (1981) Unidimensional scaling. Sage, Beverly Hills

Mensah I (2012) Environmental education and environmentally responsible behaviour: the case of international tourists in Accra hotels. Int J Tour Sci 12(3):69-89. https://doi.org/10.1080/15980 634.2012.11434664

Ministry of Water Resources, Works and Housing (2007) National Water Policy. Government of Ghana, Accra
Norris PE, Batie SS (1987) Virginia farmers' soil conservation decisions: an application of tobit analysis. South J Agric Econ 19(1987):79-89

OECD (2012) Water quality and agriculture: meeting the policy challenge. OECD studies on water. Organisation for Economic Cooperation and Development, Paris

O'Keefe D (2002) Persuasion theory and research. Sage Publications, London

Okumah M, Martin-Ortega J, Novo P (2018) Effects of awareness on farmers' compliance with diffuse pollution mitigation measures: a conditional process modelling. Land Use Policy 76:36-45

Okumah M, Chapman P, Martin-Ortega J, Novo P (2019a) Mitigating agricultural diffuse pollution: uncovering the evidence base of the awareness-behaviour-water quality pathway. Water 11(1):p29

Okumah M, Yeboah AS, Nkiaka E, Azerigyik RA (2019b) What determines behaviours towards water resources management in a rural context? Results of a quantitative study. Resources 8:109

Okumah M, Yeboah AS (2019c) Exploring stakeholders' perceptions of the quality and governance of water resources in the Wenchi municipality. J Environ Plann Manage. https://doi. org/10.1080/09640568.2019.1663724

Okumah M, Yeboah AS, Amponsah O (2020) Stakeholders' willingness and motivations to support sustainable water resources management: insights from a Ghanaian study. Conserv Sci Pract. https ://doi.org/10.1111/csp2.170

Rosseel Y (2017) The Lavaan tutorial. Department of Data Analysis, Ghent University, Ghent, Belgium. http://lavaan.ugent.be/tutorial/ tutorial.pdf. Accessed 23 Mar 2018

Silgo FX, Massey C (2007) Risk, trust and knowledge networks in farmers' learning. J Rural Stud 23(2):170-182

Steg L, Vlek C (2009) Encouraging pro-environmental behaviour: an integrative review and RESEARCH agenda. J Environ Psychol 29:309-317

Stern PC (2000) Toward a coherent theory of environmentally significant behavior. J Soc Issues 56:407-424

Stevens JP (2009) Applied multivariate statistics for the social sciences, 5 th edn. Routledge, New York, USA, Hove, UK

Ulrich-Schad JD, De Jalon SG, Babin N, Pape A, Prokopy LS (2017) Measuring and understanding agricultural producers' adoption of nutrient best management practices. J Soil Water Conserv 72:506-518

United Nations (2016a) Global sustainable development report 2016. Department of Economic and Social Affairs, New York, US

United Nations (2016b) Water and sanitation interlinkages across the 2030 agenda for sustainable development. UN-Water, Geneva, Switzerland

United Nations Environment Programme (2017) Towards a pollution free planet background report. United Nations Environment Programme, Nairobi, Kenya

United Nations World Water Assessment Programme (2015) The United Nations World Water Development Report 2015: Water for a Sustainable World. Paris United Nations Educational, Scientific and Cultural Organization

Van Riper CJ, Lum C, Kyle GT, Wallen KE, Absher J, Landon AC (2018) Values, motivations, and intentions to engage in proenvironmental behavior. Environ Behav. https://journals.sagepub.com/ doi/full/10.1177/0013916518807963\#articleCitationDownloadCo ntainer

Vrain E, Lovett A (2016) The roles of farm advisors in the uptake of measures for the mitigation of diffuse water pollution. Land Use Policy 54:413-422

Vrain E, Lovett A, Noble L, Grant F, Blundell P, Clesby W (2014) Farmer attitudes towards diffuse pollution mitigation measures in England: a demonstration test catchments report. Report to Defra. Available from: http://www.wensumalliance.org.uk/resea rch_reports/Farmer_Attitudes_December_14_\%20Final.pdf 
Warriner GK, Mcdougall GHC, Claxton JD (1984) Any data or none at all? Living with inaccuracies in self-reports of residential energy consumption. Environ Behav 16:503-526. https://doi. org/10.1177/0013916584164005

Wesselink R, Blok V, Ringersma J (2017) Pro-environmental behaviour in the workplace and the role of managers and organisation. $\mathrm{J}$ Cleaner Prod 168:1679-1687
Publisher's Note Springer Nature remains neutral with regard to jurisdictional claims in published maps and institutional affiliations. 